\title{
A new way to derive the Rodrigues formula for the Lorentz group
}

\author{
DORIN ANDRICA and RAMONA-ANDREEA ROHAN
}

\begin{abstract}
.
Using the system (1.4) in Theorem 1.1, we present in Section 3 a new way to derive the Rodrigues formula for the exponential map of the Lorentz group $\mathbf{S O}(3,1)$.
\end{abstract}

Acknowledgements. The second author was supported by the following program.

Investing in people! Ph. D. scholarship, Project co-financed by the SECTORAL OPERATIONAL PROGRAM FOR HUMAN RESOURCES DEVELOPMENT 2007 - 2013. Priority Axis 1. "Education and training in support for growth and development of a knowledge based society". Key area of intervention 1.5: Doctoral and post-doctoral programs in support of research. Contract nr. : POSDRU/88/1.5/S/60185 - "INNOVATIVE DOCTORAL STUDIES IN A KNOWLEDGE BASED SOCIETY". Babeş-Bolyai University, ClujNapoca, Romania

\section{REFERENCES}

[1] Andrica, D. and Casu, I. N., Lie Groups, Exponential Map, and Geometric Mechanics (Romanian), Cluj University Press, 2008

[2] Andrica, D. and Rohan, R.-A., The image of the exponential map and some applications, Proc. 8th Joint Conference on Mathematics and Computer Science MaCS, Komarno, Slovakia, July 14-17, 2010, 3-14

[3] Andrica, D. and Rohan, R.-A., Computing the Rodrigues coefficients of the exponential map of the Lie groups of matrices, Balkan Journal of Geometry and Applications, 18 (2013), No. 2, 1-10

[4] Bröcker, T. and Tom Dieck, T., Representations of compact Lie groups, Springer-Verlag, GTM, vol. 98, New York, 1985

[5] Chevalley, C., Theory of Lie groups I, Princeton Mathematical Series, No. 8, Princeton University Press, 1946

[6] Chin, S. A., Relativistic motion in a constant electromagnetic field, J. Math. Phys., vol. 50, 012904 (2009), 1-7

[7] Dimitrov, G. K. and Mladenov, I. M., A new formula for the exponents of the generators for the Lorentz group, $7^{\text {th }}$ International Conference on Geometry, Intergrability and Quantization, June 2-10, 2005, Varna, Bulgaria, (I. M. Mladenov and M. de León Eds.), 96-113

[8] Gallier, J., Notes on Differential Geometry and Lie Groups, University of Pennsylvannia, 2012

[9] Marsden, J. E. and Ratiu, T. S., Introduction to Mechanics and Symmetry, TAM, vol. 17, Springer-Verlag, 1994

[10] Putzer, E. J., Avoiding the Jordan canonical form in the discussion of linear systems with constant coefficients, Amer. Math. Monthly, 73 (1966), 2-7

[11] Silva Leite, F. and Crouch, P., Closed forms for the exponential mapping on matrix Lie groups based on Putzer's method, J. Math. Phys., 40 (1999), No. 7, 3561-3568

[12] Warner, F., Foundations of Differential Manifolds and Lie Groups, GTM, No. 94, Springer-Verlag, 1983

Received: 10.11.2012; In revised form: 14.02.2013; Accepted: 16.02.2013

2010 Mathematics Subject Classification. 22Exx, 22E60, 22E70.

Key words and phrases. Lie group, Lie algebra, exponential map, general linear group $\mathbf{G L}(n, \mathbb{R})$, Lorentz group $\mathbf{S O}(3,1)$, Rodrigues formula, Rodrigues coefficients.

Corresponding author: Dorin Andrica; dandrica@math.ubbcluj.ro 
BABEŞ-BOLYAI UNIVERSITY

FACULTY OF MATHEMATICS AND COMPUTER SCIENCE

CLUJ-NAPOCA, ROMANIA

E-mail address: dandrica@math.ubbcluj.ro

BABEŞ-BOLYAI UNIVERSITY

FACULTY OF MATHEMATICS AND COMPUTER SCIENCE

CLUJ-NAPOCA, ROMANIA

E-mail address: ramona. rohan@ubbcluj.ro 